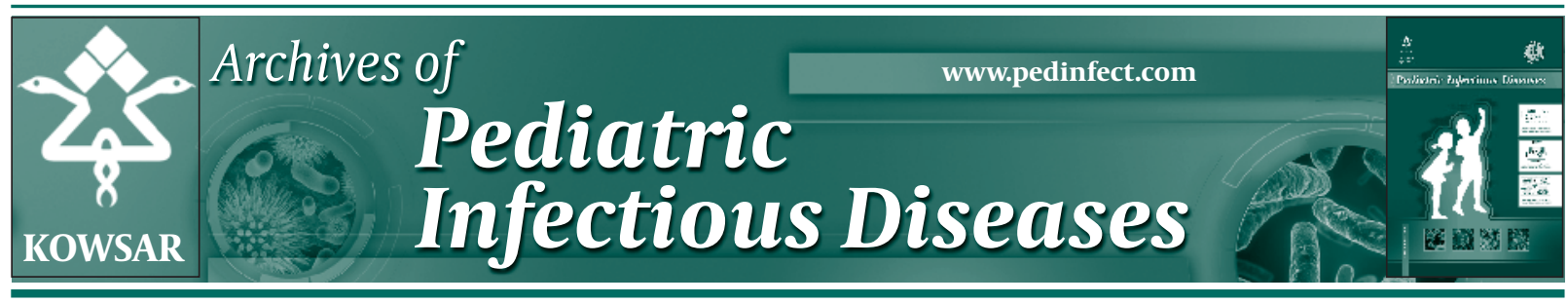

\title{
Is Urinary Beta-2 Microglobulin a Good Predictive Marker in Children With Pyelonephritis?
}

\author{
Behnam Sobouti ${ }^{1,}$, Yaser Ghavami ${ }^{2}$ \\ ${ }^{1}$ Ali- Asghar Hospital, Tehran University of Medical Sciences, Tehran, IR Iran \\ 2 Burn Research Center, Tehran University of Medical Sciences, Tehran, IR Iran \\ * Corresponding author: Behnam Sobouti, Ali- Asghar Hospital, Tehran University of Medical Sciences, Tehran, IR Iran.Tel.: +98-9111531822, Fax: +98- \\ 2122220063, E-mail: bsobooti@tums.ac.ir
}

Keywords: Beta 2-Microglobulin; Pyelonephritis

\section{DearEditor,}

Regarding recently published article on urinary beta-2 microglobulin (ß2MG) as a prognostic marker in children with pyelonephritis, some issues should be considered (1). ß2MG is a small globular peptide with a molecular weight of 11800 Dalton which can be found on the surface of many cells. It consists of 100 amino acids with a disulfide-linked loop between amino acid 25 and 81; and its tertiary structure is homologous to the $\mathrm{CH} 3-$ IgG domain. ß2MG passes freely through the glomerular membrane. Thereafter it is reabsorbed to an amount of maximum $99.9 \%$ by the proximal tubules (2). In aforementioned interesting article, the relation between urinary ß2M to Creatinine ratio and its effect on kidney damage may not be an incidental finding. Although it is possible to apply ß2M as a prognostic factor in patients with pyelonephritis, but exclusion criteria for patients should be extended more than mentioned. Other contributing factors in increased $\mathrm{B}_{2 \mathrm{M}}$ are infections (such as CMV and HIV), malignancies (i.e. multiple myeloma), exposure to heavy metals (Mercury, Cadmium), kidney transplant, amyloidosis and drugs (such as Lithium, Cyclosporine, Cisplatin, Aminoglycosides). These issues should be taken into account and are considered in the exclusion criteria (3-6).

\section{Authors' Contribution}

None declared.

\section{Financial Disclosure}

None declared.

\section{References}

1. Sharifian M, Karimi A, Mohkam M, Dalirani R, Esfandiar N, Tabatabaei SR, et al. Urinary Beta 2-Microglobulin as a Prognostic marker in children with pyelonephritis. Arch Pediatr Infect Dis. 2012;1(1):18-22.

2. Lehmann CA. Saunders manual of clinical laboratory science. 1998.

3. Del Palacio M, Romero S, Casado JL. Proximal tubular renal dysfunction or damage in HIV-infected patients. AIDS Rev. 2012;14(3):179-87.

4. Heegaard NH. Beta(2)-microglobulin: from physiology to amyloidosis. Amyloid. 2009;16(3):151-73.

Article type: Letter; Received: 01 Jan 2013 , Accepted: 07 Jan 2013; DOI: 10.5812/pedinfect.10074

-Please cite this paper as:

Sobouti B, Ghavami Y. Is Urinary Beta-2 Microglobulin a Good Predictive Marker in Children With Pyelonephritis? Arch Pediatr Infect Dis.2013;1(2):105-106. DOI:10.5812/pedinfect.10074 
5. Liabeuf S, Lenglet A, Desjardins L, Neirynck N, Glorieux G, Lemke $\mathrm{HD}$, et al. Plasma beta-2 microglobulin is associated with cardiovascular disease in uremic patients. Kidney Int. 2012;82(12):1297303.
6. Yang J, Qian J, Wezeman M, Wang S, Lin P, Wang M, et al. Targeting beta2-microglobulin for induction of tumor apoptosis in human hematological malignancies. Cancer Cell. 2006;10(4):295307. 